\title{
Potential of small-scale and structurally diverse short-rotation coppice as habitat for large and medium-sized mammals
}

\author{
Felix Zitzmann $^{1}$ (D) $\cdot$ Michael Reich $^{1} \cdot$ Frank Schaarschmidt $^{2}$ \\ Received: 9 June 2020 / Accepted: 14 January 2021 / Published online: 1 March 2021 \\ (C) The Author(s) 2021
}

\begin{abstract}
We surveyed occurrence and activity of large and medium-sized mammals on three experimental short-rotation coppice (SRC) and three afforestations by camera trapping. Both habitat types were surveyed simultaneously in spring. Additional wintertime surveys were performed on the SRC to consider seasonal aspects of habitat utilisation. In spring, SRC and afforestations were predominantly used by the same species. European hare (Lepus europaeus) and roe deer (Capreolus capreolus) were the most active species across all sites. Additionally, the European rabbit (Oryctolagus cuniculus) showed intense activity on one SRC site. Activity of carnivorous and omnivorous species was comparatively low in both habitat types, but even lower on the SRC. The only forest-associated species (European badger Meles meles), detected on all afforestations, was absent from the SRC. In winter, the surveyed SRC were used by the same species as in spring. Most species showed similar activity on the SRC in both seasons. We conclude that small-scale and structurally diverse SRC provide suitable habitat, in different seasons, especially for herbivorous mammals associated with farmland and forest-ecotones rather than forest species. The extent to which our results can be generalised to large-scale commercial SRC is unclear. However, the results indicate that SRC can be managed in a manner compatible with wildlife and may then have a habitat function for mammals comparable to that of young afforestations. Creation of within-plantation heterogeneity can be a suitable measure to improve habitat quality and should, therefore, be considered in the design and management of SRC.
\end{abstract}

Keywords Perennial woody biomass crops $\cdot$ Bioenergy $\cdot$ Biodiversity $\cdot$ Wildlife $\cdot$ Game $\cdot$ Camera trapping

\section{Introduction}

Renewable energy from biomass cultivation has significantly expanded in recent decades in order to reduce the consumption of fossil fuels and greenhouse gas emissions (Edenhofer et al. 2012). However, the cultivation mostly employs intensively managed, first-generation annual biomass crops that can have considerable negative effects on the environment and biodiversity (Huston and Marland 2003; Robertson et al. 2008; Eggers et al. 2009; Meehan et al. 2010; Fletcher et al. 2011; Everaars et al. 2014; Immerzeel et al. 2014; Sauerbrei

Felix Zitzmann

zitzmann@umwelt.uni-hannover.de

1 Institute of Environmental Planning, Leibniz University Hannover, Herrenhäuser Str. 2, 30419 Hannover, Germany

2 Institute of Cell Biology and Biophysics, Biostatistics department, Leibniz University Hannover, Herrenhäuser Str. 2, 30419 Hannover, Germany et al. 2014). Alternatively, different perennial biomass crops can offer a more sustainable land-use option (Lewandowski 2016; Englund et al. 2020). One of these second-generation biomass crops are short-rotation coppice (SRC). These are plantations of fast-growing trees (typically hybrids of poplar or willow) that are harvested in 3-5 year cycles and utilised usually for their dendromass for energy production (Dimitriou and Rutz 2015).

Establishing SRC on arable land leads to a significant change in habitat characteristics and therefore provides new habitat for wildlife on farmland (Christian et al. 1994; Sage 1998). Studies on biodiversity of these crops have shown positive effects compared to intensively managed arable land, especially in cleared agricultural landscapes and on structurally diverse plantations (Baum et al. 2009; Rowe et al. 2009; Schulz et al. 2009; Vanbeveren and Ceulemans 2019). These previous studies primarily focused on breeding birds, carabid beetles and vascular plants. In contrast, studies focusing on the habitat function for mammals are rare and have a distinct focus on small mammals (Christian et al. 1997, 1998; 
Coates and Say 1999; Moser et al. 2002; Giordano and Meriggi 2010; Campbell et al. 2012). The few studies concerning large and medium-sized mammals on SRC (Christian 1997; Sage and Tucker 1998; Bergström and Guillet 2002; Schulz et al. 2008; Fry and Slater 2009) are either based on the detection of characteristic tracks or merely document observations made during field work on other species groups. Hence, their findings are mainly based on indirect detections over short survey periods and accidental observations, rather than on long term systematic surveys. Knowledge about the habitat use and quality of SRC for large and medium-sized mammals is, therefore, still limited. Considering the possible increase in SRC cultivation, in the context of expansion of renewable energies from biomass (Rowe et al. 2009; Don et al. 2012), more knowledge is needed to guide such development in an environmentally sound way and to incorporate biodiversity concerns into the crop management (Sage 1998; Dauber et al. 2010).

The aims of our investigation were therefore to determine (i) which large and medium-sized mammal species integrate small-scale and structurally diverse SRC into their habitat utilisation, (ii) how frequently and intensively these plantations are used by those species and (iii) which seasonal aspects of habitat use and activity exist. Furthermore, we want (iv) to evaluate the habitat function of these SRC in comparison to afforestations, which represent woody habitats with a similar vegetation structure and age as SRC and which are commonly implemented measures for wildlife conservation in agricultural landscapes. Based on our results, recommendations are given for a mammal-friendly design and management of SRC.

\section{Materials and methods}

\section{Study area and study sites}

Surveys were conducted from November 2018 to January 2019 and from March to June 2019 on three SRC and three deciduous afforestations in the municipality of Schapen, in the southern part of the county of Emsland (Lower Saxony, Northwestern Germany). Study sites were located between 1 and $5.5 \mathrm{~km}$ apart (Fig. 1). The landscape in this region is dominated by intensive agricultural use (approx. 70\%, predominantly arable land) and contains a relatively low (14\%) proportion of woodland (Gepp 2015; Landkreis 2016). The area surrounding the individual study sites was also dominated by open habitat, in particular arable land (Table 1, Fig. 1). Distance to larger ( $>10 \mathrm{ha}$ ) forested areas was between 500 and $1500 \mathrm{~m}$ for all sites, except for afforestation $\mathrm{C}$, which bordered directly on a larger forested area. In addition, one SRC and one afforestation were situated right next to smaller established woodland (of at least 1 ha in size), while the other three sites were situated at a greater distance $(>600 \mathrm{~m})$ to the next smaller woodland.

The three SRC sites were established at the beginning of 2011 and 2012. They are experimental sites that were established to investigate the suitability of SRC as an alternative measure for wildlife conservation (Wagener et al. 2013). Therefore, these sites are managed less intensively (no use of fertilisers and pesticides) and are particularly diverse in terms of their structural characteristics in comparison to large-scale commercial SRC. Beneath clones of poplar (Max 3, Hybride 275) and willow (Inger, Tordis), some native woody species were each planted in blocks of $20 \mathrm{~m}$ width (Table 1, Fig. 2). Planting density varied between 5000 (Betula pendula) and 12,000 (willows) stools per hectare, depending on the tree species. Crops are annually only partially harvested, creating a mixture of different age classes (Figs. 2 and 3). Smaller parts $(<0.5 \mathrm{ha})$ of the willow and poplar stands were harvested, for the very first time, in February 2018 and in February 2019. At the time of the study, regrowth of recently cut stands showed heights of up to a maximum of $1 \mathrm{~m}$, while stands cut in the previous year reached heights of 2-4 m. The so far uncut willow and poplar stands had grown to heights of 10 up to $15 \mathrm{~m}$.

The three afforestations were established at the end of 2012 as measures for wildlife conservation. Different native tree species were planted in varying proportions on each site (Table 1). In addition, various shrubs such as Crataegusand Salix-species, Corylus avellana, Euonymus europaeus, Sorbus aucuparia and Prunus spinosa were planted at the margins of the sites. Planting density varied between 6000 and 7000 stools per hectare. Height varied according to species type and site and ranged between 3 and $5 \mathrm{~m}$ at the time of the study.

Both afforestations and SRC contained some smaller gaps but also larger open areas with the character of clearings due to the failure of trees and shrubs to grow. In addition, rides, and in the case of the SRC, harvested plots and headlands, increased the structural diversity of the sites.

\section{Survey methods}

We used camera traps (CTs) to observe large and mediumsized mammals on the study sites. CTs are camera systems which are automatically triggered by motion and infraredsensors once an animal of sufficient size is present within the detection area. Due to the similar vegetation structures, the conditions for detectability using CTs in the surveyed habitat types are virtually identical and the results are therefore easily comparable (cf. O'Connell et al. 2011; Burton et al. 2015). Four CTs, either "Dörr Snapshot Limited Black 5.0S" or "Dörr Snapshot Extra 5.0 MP" models, were installed on each study site. Both models are able to record at night and 


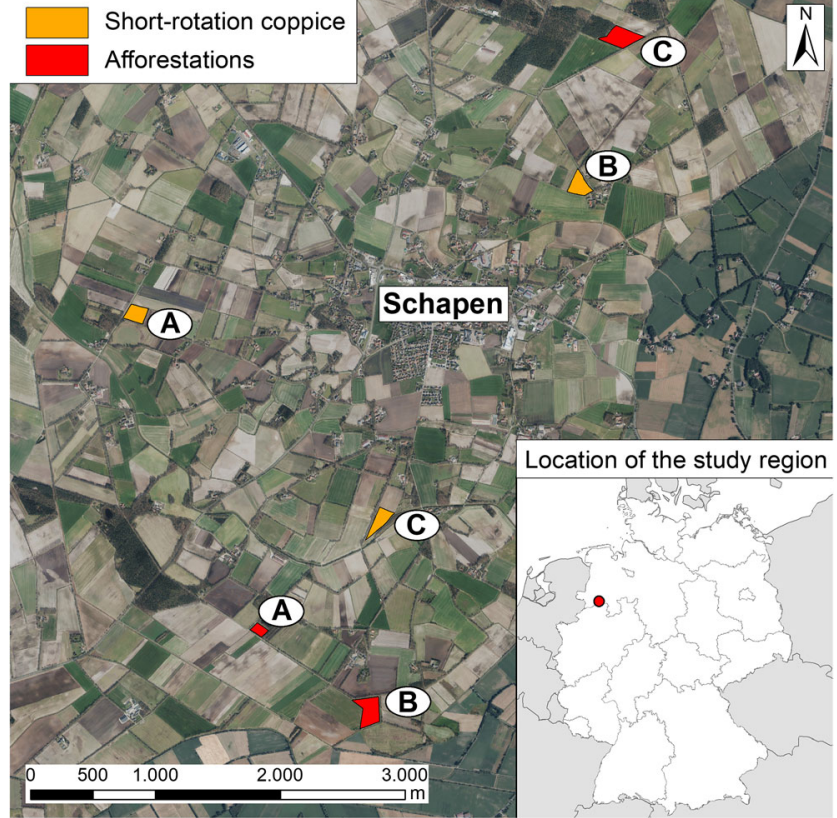

Fig. 1 Location of the study region in Germany and location of the study sites in the municipality of Schapen

at dawn and are almost identical in terms of their basic technical features.

The four CTs were placed between differently structured sub-areas (e.g. borders between woody stands and clearings/ rides, between stands of different clones/woody species, or between stands of different age classes) on each site. A minimum distance of $30 \mathrm{~m}$ was set between the individual CTs in order to distribute them as evenly as possible over the sites. The exact position of the CTs at the borders of differently structured sub-areas was selected randomly. CTs were attached to trees or rods, with the camera lens at a height of $55 \mathrm{~cm}$. The number of images generated per trigger was set to three, meaning that a series of three images was created during a single triggering event. This facilitates the subsequent identification and determination of mammal species on the images. Delay between two consecutive triggers was set to $5 \mathrm{~s}$. Sensitivity of the motion sensor was set to high. CTs were active one hour before sunset to one hour after sunrise since the main activity of most mammal species is at dawn and night. CTs were controlled every 10-20 days. Surveys were conducted in winter (SRC only) from 28 November 2018 to 10 January 2019 (43 nights) and in spring (SRC and afforestations) from 20 March 2019 to 19 June 2019 (91 nights). On the SRC, different positions for the CTs were used in different seasons, i.e. after the winter surveys the CTs were again randomly distributed between differently structured sub-areas for the springtime surveys.

Exposure time of the $24 \mathrm{CTs}$ used during spring was a total of 2083 camera nights, thereof 1031 (49.5\%) on the SRC and 1052 (50.5\%) on the afforestations. Per study site, all four CTs were active between 328 and 364 camera nights. The number of active camera nights per $\mathrm{CT}$ varied slightly due to individual technical failures, but differences between SRC ( $85.9 \pm$ 8.7 SD) and afforestations ( $87.7 \pm 4.1)$ were negligible. During the wintertime survey period, all 12 CTs used on the SRC remained fully functional and were active for 43 nights each. The total exposure time of all CTs used in winter was 516 camera nights (172 per site).

\section{Data preparation and statistical analysis}

After finishing camera trapping, the relevant information from the series of images with visible large and mediumsized mammals was transferred into a table for further statistical analysis. Thereby, one detection always consists of a series of three consecutive images (see CT settings).

Table 1 Characteristics of the study sites

\begin{tabular}{|c|c|c|c|c|c|c|}
\hline \multirow[t]{2}{*}{ Habitat type } & \multirow[t]{2}{*}{ Site } & \multirow[t]{2}{*}{ Size [ha] } & \multirow[t]{2}{*}{ Woody species } & \multirow{2}{*}{$\begin{array}{l}\text { Ratio woody to } \\
\text { open habitat }^{1}\end{array}$} & \multicolumn{2}{|c|}{ Distance $[\mathrm{m}]$ to next woodland ${ }^{2}$} \\
\hline & & & & & $\geq 1$ ha & $>10$ ha \\
\hline \multirow[t]{3}{*}{$\mathrm{SRC}$} & A & 2.0 & $\begin{array}{l}\text { Populus Max 3/Hybride } 275 \text {, Salix Inger/Tordis, } \\
\text { Sorbus aucuparia, Betula pendula }\end{array}$ & 0.09 & adj. & 1500 \\
\hline & $\mathrm{B}$ & 2.2 & $\begin{array}{l}\text { P. max } 3 / \text { Hybride } 275, S \text {. Inger/Tordis, } S \text {. aucuparia, } \\
\text { B. pendula, Alnus glutinosa }\end{array}$ & 0.05 & 600 & 800 \\
\hline & $\mathrm{C}$ & 2.0 & $\begin{array}{l}\text { P. Max } 3, S \text {. Inger/Tordis, S. aucuparia, B. pendula, } \\
\text { A. glutinosa, A. incana }\end{array}$ & 0.13 & 800 & 1400 \\
\hline \multirow[t]{3}{*}{ Afforestations } & A & 0.9 & B. pendula, Fagus sylvatica, Quercus robur & 0.1 & adj. & 500 \\
\hline & $\mathrm{B}$ & 3.2 & Acer pseudoplatanus, $Q$. robur, Q. petraea, Carpinus betulus & 0.11 & 850 & 1500 \\
\hline & $\mathrm{C}$ & 3.4 & Q. robur, Q. petraea, B. pendula, C. betulus, $F$. sylvatica & 0.3 & adj. & adj. \\
\hline
\end{tabular}

\footnotetext{
${ }^{1}$ Ratio of the area of woody habitat (woodland, groves, shrubs, hedges) to the area of open habitat (arable land, grassland, fallow land) within a radius of $500 \mathrm{~m}$ around each site

${ }^{2}$ Distance to the next established woodland of smaller size (at least 1 ha) and distance to the next larger forested area $(>10$ ha), adj. $=$ adjacent
} 
Fig. 2 Aerial view on one of the SRC study sites (site B). The species-specific cultivation units, each $20 \mathrm{~m}$ in width, with different poplar and willow hybrids (in different age classes) and different native woody species are clearly visible (Recording date: June 2019)

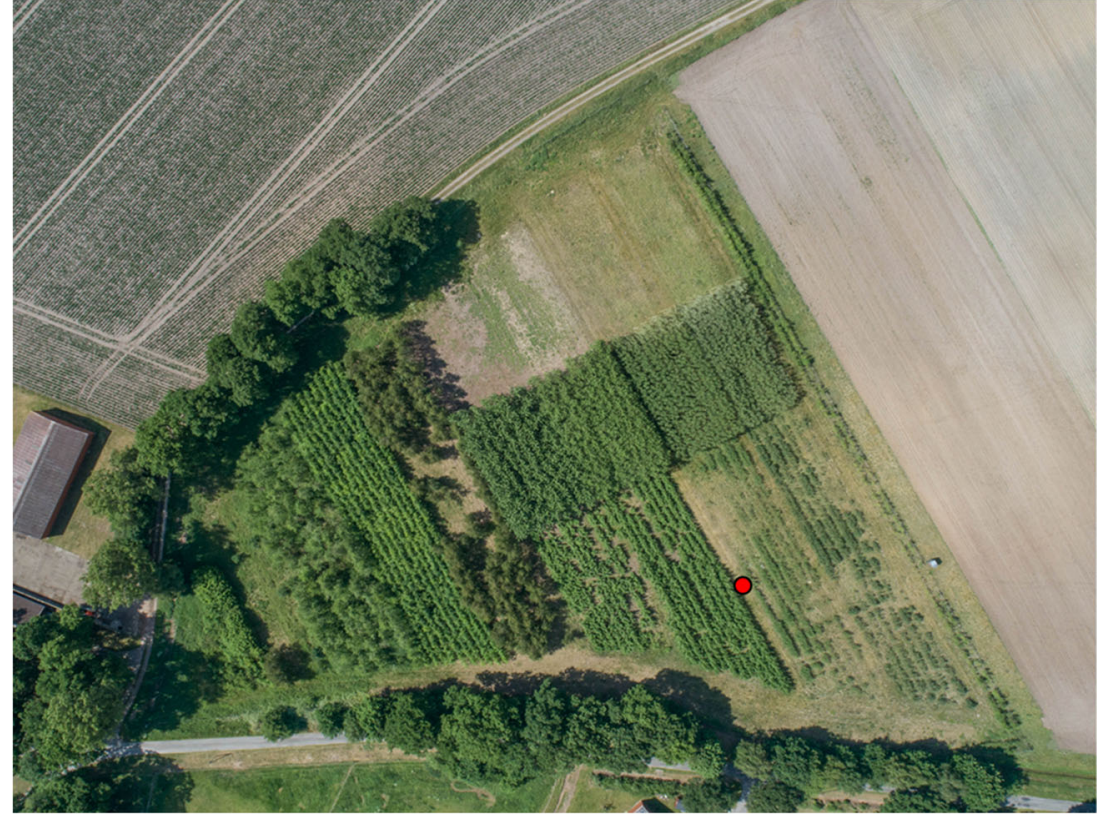

Only images with mammal species of at least the size of a red squirrel (Sciurus vulgaris L., 1758) were taken into account. Images of smaller mammals (mostly Muroidea) were excluded from further consideration, as were images without any visible mammal species, images of birds and human-induced images. Since domestic mammals were not the objective of our study, detections of cats (Felis silvestris catus L., 1758) and dogs (Canis lupus familiaris L., 1758) were also excluded. For each detection, the date and time of the detection, the specific position of the CT on the particular study site and the mammal species shown on the particular series of images was documented (as long as this was determinable on basis of the photographic material).
On this basis, species numbers were calculated per habitat type (SRC and afforestation), per study site and per CT (total no. of species per CT and no. of species per CT per camera night). Furthermore, the following indices were calculated as indicators for the spatial and temporal use of the study sites by the different species. One camera night is thereby defined as the time frame from $1 \mathrm{~h}$ before sunset to $1 \mathrm{~h}$ after sunrise the following day.

- The Detection Rate (DR) indicates the number of detections per $\mathrm{CT}$ in relation to 100 camera nights (cf. Burton et al. 2015). We consider the $D R$ as an indicator of the use intensity (cf. Armenteros et al. 2020). $D R$ is given for the individual species and cumulatively for all species
Fig. 3 Different age classes of poplar (left) and willow (right) hybrids on site $\mathrm{B}$. The red dot in Fig. 2 indicates the point of view while taking the image

(Recording date: May 2019)

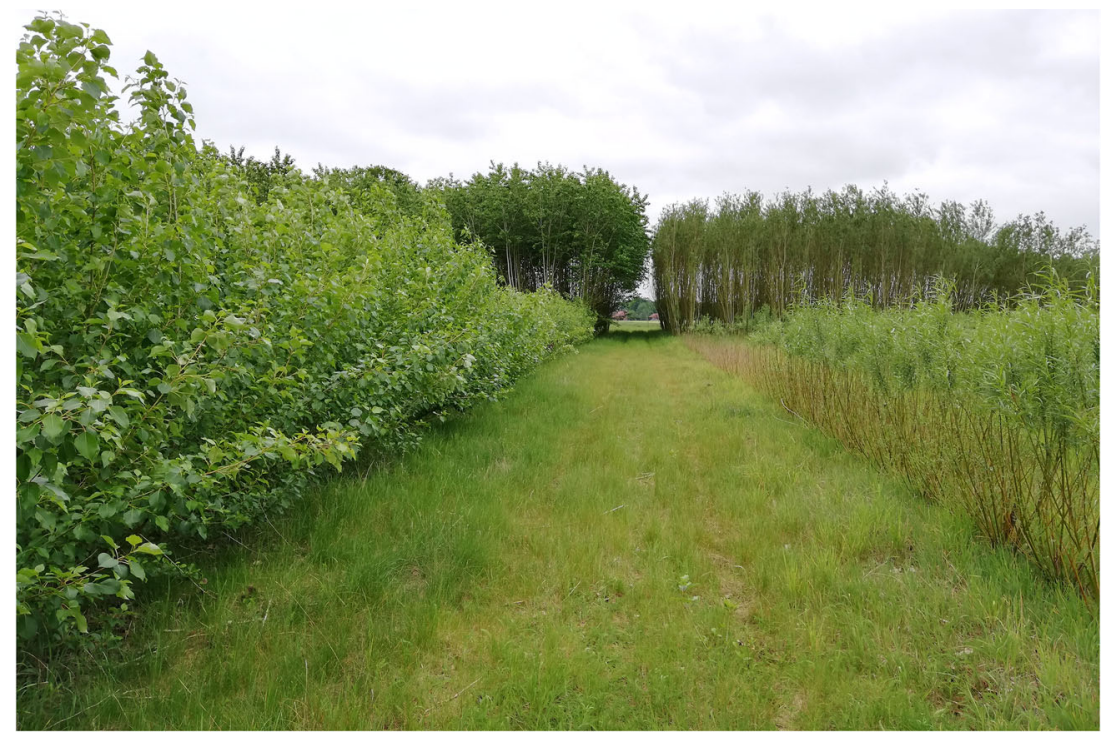


together (overall $D R$ ). It is calculated by $\mathrm{DR}=($ no. of detections/no. of active camera nights) $\times 100$.

- The Temporal Presence Rate (TPR) indicates the proportion of active camera nights that a particular species has been recorded. Therefore, the number of detections is irrelevant. Only presence/absence of each species per camera night is taken into account. TPR is considered as an indicator of the visit frequency (cf. Armenteros et al. 2020) and is calculated per CT and per study site (cumulatively for $4 \mathrm{CTs}$ ). It is calculated by $T P R=$ (no. of nights with presence of the species $\times 100) /$ no. of active camera nights.

- As an indicator for the extent of spatial utilisation of the study sites by the species found, Spatial Presence Rate, i.e. the number of CTs ( $n=12$ per habitat type) by which a particular species has been detected during the study period, was determined.

The number of detections per CT were modelled using generalised estimating equations (GEE), with log-link, assuming the Poisson distribution with extra-Poisson variability, with the difference between the habitat types (SRC and afforestations) as a fixed effect (Hardin and Hilbe 2013). To account for repeated measurements from the same site, an exchangeable correlation structure was assumed for observations within the same site. $D R$ (both for the different species and cumulatively for all species together) were estimated as a ratio to the number of active camera nights, by including the log number of active camera nights as an offset into the model (see description of activity-indices above). This leads to estimated rates corrected for the possibility of different numbers of active camera nights per CT. Based on the fitted model parameters, an asymptotic test for the difference between the habitat types (springtime surveys) was performed on the link scale, with the null hypothesis of equal rates between SRC and afforestations, and the alternative hypothesis of different rates between both habitat types. The total number of species per CT was analysed using the same methods as for the detections per CT, but without using the number of active camera nights as an offset. For the analysis of $T P R$, the number of nights with species present and absent was modelled in a GEE assuming the binomial distribution with extra-binomial variability, with logit link, season as a fixed effect, and assuming exchangeable correlation structure for observations from the same site. Based on the estimated model parameters, asymptotic tests were performed for the null hypothesis of equal TPR between SRC and afforestations, vs. the alternative hypothesis of different $T P R$ between both habitat types.

For the comparison of seasonal aspects (winter vs. spring) of habitat utilisation within the SRC, we used GEE models with the same assumptions, links and offset specifications as described above, except that the exchangeable correlation structure was for observations within the same site and season. Hypotheses tests following these models tested the null hypothesis of equal rates between seasons vs. the alternative of different rates between seasons.

Model fitting and subsequent statistical testing was performed in R Version 3.6.1 (R Core Team 2019), using $R$ package geepack (version 1.2-1, Halekoh et al. 2006) and package emmeans (version 1.4, Lenth et al. 2019) for model based comparison of habitat types or seasons.

\section{Results}

\section{Springtime surveys on SRC and afforestations}

Between March and June 2019, a total of 4840 detections of large and medium-sized mammals were made, 2576 (53.2\%) of them on the SRC and 2264 (46.8\%) on the afforestations. 4696 (97\%) detections could be determined up to species level, another $19(0.4 \%)$ up to genus level (Martes) and 108 (2.2\%) up to family level (Leporidae or Mustelidae). For 17 detections $(0.4 \%)$ determination was not possible due to poor image quality.

A total of eight species were detected (Table 2), seven of them on the SRC and six on the afforestations. For each SRC site, 4-6 species were found, and for each afforestation site 56 species. Total species number per CT (Table 4 ) was considerably higher on afforestations $(4.42 \pm 1.0)$ than on SRC (3.42 $\pm 1.0)(p<0.0001)$. Number of species per CT per camera night did not differ between both habitat types $(p=0.70)$. Five species - European hare (Lepus europaeus), roe deer (Capreolus capreolus), beech marten (Martes foina), red fox (Vulpes vulpes) and European hedgehog (Erinaceus europaeus) - were found in both habitat types. European badger (Meles meles) was only detected on the afforestations, while European rabbit (Oryctolagus cuniculus) and European polecat (Mustela putorius) were only found on the SRC (Table 2).

On the afforestations, five out of six species (roe deer, hare, red fox, badger, beech marten) were detected on all three sites and by more than half of the CTs used. In comparison, on the SRC, only three species (hare, roe deer, beech marten) were detected on all three sites by more than half of the CTs used. The four remaining species were detected only on one (red fox, polecat) or two (rabbit, hedgehog) sites and only by a few CTs.

Activity of most species was extremely variable in both habitat types (see extremely high SD for $D R$ and $T P R$ in Table 4) and there were sometimes considerable differences in activity between different sites and in some cases, even more extreme differences in activity between different CTs on one and the same site. CTs located at the borders between open habitat features, such as headlands or rides, and woody stands, showed especially high numbers of detections in both 
Table 2 List of species detected per habitat type (SRC and afforestations) and season (SRC in winter and in spring) and proportion of species-specific detections of the total number of detections per habitat type and season (cumulative detections of all 12 CTs used per type)

\begin{tabular}{|c|c|c|c|}
\hline Species name & SRC_WINTER & SRC_SpRING & AFFORESTATIONS \\
\hline \multirow[t]{2}{*}{ Europ. hare Lepus europaeus (Pallas, 1778) } & $60.9 \%(12)$ & $52.9 \%(12)$ & $40.4 \%(11)$ \\
\hline & $\square=\mathbf{m}$ & घ घ & a $\square$ \\
\hline \multirow[t]{2}{*}{ Roe deer Capreolus capreolus (L., 1758) } & $24.3 \%(12)$ & $25.7 \%(12)$ & $55.6 \%(12)$ \\
\hline & $\square=$ & m घ & $\square \square$ \\
\hline \multirow[t]{2}{*}{ Europ. rabbit Oryctolagus cuniculus (L., 1758) } & $11.2 \%(4)$ & $14 \%(3)$ & - \\
\hline & - & ! & \\
\hline \multirow[t]{2}{*}{ Beech marten Martes foina (Erxleben, 1777) } & $0.6 \%(2)$ & $0.8 \%(7)$ & $1 \%(7)$ \\
\hline & - & $\square \square$ & $\square \square$ \\
\hline \multirow[t]{2}{*}{ Red fox Vulpes vulpes (L., 1758) } & $0.3 \%(3)$ & $0.1 \%(2)$ & $1.1 \%(8)$ \\
\hline & a & घ & $\square$ घ \\
\hline \multirow[t]{2}{*}{ Europ. hedgehog Erinaceus europaeus (L., 1758) } & - & $0.08 \%(2)$ & $0.09 \%(2)$ \\
\hline & & घ & - \\
\hline \multirow[t]{2}{*}{ Europ. badger Meles meles (L., 1758) } & - & - & $1.5 \%(11)$ \\
\hline & & & $\square \square$ \\
\hline \multirow[t]{2}{*}{ Europ. polecat Mustela putorius (L., 1758) } & $0.3 \%(3)$ & $0.04 \%(1)$ & - \\
\hline & ! & - & \\
\hline No. of species per site (site $\mathrm{A} / \mathrm{B} / \mathrm{C}$ ) & $4 / 3 / 5$ & $6 / 4 / 5$ & $6 / 5 / 5$ \\
\hline No. of species per habitat type/season & 6 & 7 & 6 \\
\hline
\end{tabular}

- / I I = Detections on one, two or three sites of the particular type; In brackets: Spatial presence rate, i.e. number $(\mathrm{n} / 12)$ of camera traps with detections of the particular species. Detections that were not determinable to the species level are not included and are missing to $100 \%$ habitat types. This became particularly clear during the springtime surveys on the SRC. On two sites (A and C), single CTs located at the borders between rides and woody stands were responsible for 71 and $75 \%$ of all detections made on these sites. The overall $D R$ (all species considered) per CT was slightly higher for SRC $(246.9 \pm 318.3)$ than for afforestations $(216.1 \pm 130.1)$. However, differences were not significant $(p=0.62)$. For the five species detected in both habitat types, there were only minor differences in activity between the two habitat types for hare, beech marten and hedgehog. In contrast, roe deer and red fox were considerably more active on afforestations than on SRC (see species-specific results).

\section{Wintertime surveys and seasonal aspects of habitat utilisation on SRC}

In total, 906 detections of large and medium-sized mammals were made during the wintertime survey period between November 2018 and January 2019. Image series of 889 (98.1\%) detections were identified to species level, six to genus level (Martes) and another six to family level (Leporidae and Mustelidae). For five detections, identification was not possible.

A total of six large and medium-sized mammal species were found on the three SRC during winter (Table 2). Except for the hedgehog, which hibernates, these were the same species as recorded in spring. For each SRC site, slightly fewer species were detected in winter ( $3-5$ species) than in spring (4-6 species). Total species number per CT was $3.25 \pm$ 0.87 , and therefore only slightly lower than in spring (3.42 \pm 1.0) $(p=0.67)$. Number of species per CT per camera night also did not differ between the seasons $(p=0.59)$.

As in spring, the activity of most species was highly variable (Table 4). Overall $D R$ per CT was lower in winter (175.6 $\pm 128.9)$ than in spring $(246.9 \pm 318.3)$. However, extremely high values recorded by single CTs, especially in spring, strongly influenced the mean. The medians were much closer (winter 114, spring 134). Therefore, difference in overall $D R$ between the seasons was not significant $(p=0.22)$. In addition, activity of the individual species mainly differed slightly between the seasons (see species-specific results).

\section{Species-specific results}

\section{European hare and roe deer}

Both in spring (SRC and afforestations) and in winter (SRC), hare and roe deer were found across all study sites and were by far the most active species with regard to their number of detections and their temporal presence (Tables 2, 3 and 4). Hares were responsible for a total of 2277 detections in spring, of which 1363 (59.9\%) were made on the SRC and 914 $(40.1 \%)$ on the afforestations. On two SRC, hares were recorded in more than $90 \%$ of nights, while on the third SRC hares were detected in only $37 \%$ of nights. On the afforestations, hares were recorded in slightly fewer nights (Table 3 ). 
Both activity indices, however, showed only minor differences between the habitat types $(D R: p=0.41 ; T P R$ : $p=0.64)$. Hare activity on the SRC was similar in winter and in spring ( $D R: p=0.57$; TPR: $p=0.42$ ). In winter, the species was detected in $81-86 \%$ of nights per site. The proportion of nights with presence of hares was therefore at a comparably high level in both seasons, but more balanced between the three sites in winter.

Roe deer were detected 1920 times in spring, including $1258(65.5 \%)$ detections on the afforestations and 662 (34.5\%) detections on the SRC. The proportion of nights with roe deer detections was slightly higher on the afforestation sites $(60-78 \%)$ than on the SRC sites (46-64\%). Likewise, the means of both activity indices per $\mathrm{CT}$ were higher on the afforestations. Differences in $D R$ were significant $(p=0.032)$, while differences in $T P R$ were considerable but not significant $(p=0.078)$. In winter, roe deer were detected in fewer nights per SRC site (37-47\%) than in spring. Therefore, TPR was significantly higher in spring $(p=0.0001)$. Differences in $D R$ were not significant between both seasons $(p=0.17)$.

Table 3 Temporal presence (in \% of nights surveyed) of the mammal species per study site (aggregated value of all 4 CTs used per site)

\begin{tabular}{|c|c|c|c|c|}
\hline \multirow[t]{2}{*}{ Species name } & & \multicolumn{3}{|c|}{ Presence per study site } \\
\hline & & $\mathrm{A}$ & $\mathrm{B}$ & $\mathrm{C}$ \\
\hline \multirow[t]{3}{*}{ Europ. hare } & $\mathrm{SRC}^{\mathrm{W}_{\mathrm{INTER}}}$ & 81.4 & 81.4 & 86.0 \\
\hline & $\mathrm{SRC}^{\mathrm{S}_{\text {PRING }}}$ & 90.1 & 37.4 & 91.2 \\
\hline & AFFOREST & 58.2 & 80.2 & 36.3 \\
\hline \multirow[t]{3}{*}{ Roe deer } & $\mathrm{SRC}^{\mathrm{W}_{\text {INTER }}}$ & 46.5 & 37.2 & 37.2 \\
\hline & $\mathrm{SRC}^{\mathrm{S}_{\text {PRING }}}$ & 46.2 & 63.7 & 60.4 \\
\hline & AFFOREST & 78.0 & 60.4 & 64.8 \\
\hline \multirow[t]{2}{*}{ Europ. rabbit } & $\mathrm{SRC}^{\mathrm{W}_{\text {INTER }}}$ & - & - & 76.7 \\
\hline & $\mathrm{SRC}^{\mathrm{S}_{\text {PRING }}}$ & 1.1 & - & 72.5 \\
\hline \multirow[t]{3}{*}{ Beech marten } & $\mathrm{SRC}^{\mathrm{W}_{\text {INTER }}}$ & - & 7.0 & - \\
\hline & $\mathrm{SRC}^{\mathrm{S}_{\text {PRING }}}$ & 7.7 & 3.3 & 6.6 \\
\hline & AFFOREST & 5.5 & 2.2 & 3.3 \\
\hline \multirow[t]{3}{*}{ Red fox } & $\mathrm{SRC}^{\mathrm{W}_{\text {INTER }}}$ & 4.7 & - & 2.3 \\
\hline & $\mathrm{SRC}^{\mathrm{S}_{\text {PRING }}}$ & - & 3.3 & - \\
\hline & AFFOREST & 2.2 & 5.5 & 9.9 \\
\hline \multirow[t]{2}{*}{ Europ. hedgehog } & $\mathrm{SRC}^{\mathrm{S}_{\text {PRING }}}$ & 1.1 & - & 1.1 \\
\hline & AFFOREST & 2.2 & - & - \\
\hline Europ. badger & AFFOREST & 9.9 & 5.5 & 6.6 \\
\hline \multirow[t]{2}{*}{ Europ. polecat } & $\mathrm{SRC}^{\mathrm{W}_{\text {INTER }}}$ & - & - & 7.0 \\
\hline & $\mathrm{SRC}^{\mathrm{S}_{\text {PRING }}}$ & 1.1 & - & - \\
\hline \multirow[t]{3}{*}{ Carnivores and omnivores $^{\mathrm{a}}$} & $\mathrm{SRC}^{\mathrm{W}_{\text {INTER }}}$ & 9.3 & 16.3 & 9.3 \\
\hline & $\mathrm{SRC}^{\mathrm{S}_{\text {PRING }}}$ & 15.4 & 11.0 & 11.0 \\
\hline & AFFOREST & 22.0 & 12.1 & 22.0 \\
\hline
\end{tabular}

${ }^{\text {a }}$ Cumulative detections of the species red fox, badger, hedgehog, beech marten, polecat and members of the Mustelidae family which were not determinable to the species level due to poor image quality

\section{European rabbit}

In spring, rabbits were found on two SRC. On one of these sites, rabbits were highly active and were detected in $72.5 \%$ of nights. On the second site there were only a few detections in one single night. In winter, rabbits were found on one SRC. On this particular site, the species was recorded in $76.7 \%$ of nights and therefore was detected as frequently as in spring. Consequently, activity did not differ between both seasons (TPR: $p=0.86 ; D R$ : $p=0.61)$.

\section{Carnivorous and omnivorous species}

Overall, the activity of carnivorous and omnivorous species was relatively low in comparison to the activity of herbivorous species across all study sites of both habitat types (Tables 3 and 4). With regard to the comparison of both habitat types, cumulative activity of carnivorous and omnivorous species was significantly higher on afforestations (DR: $p=0.028$; TPR: $p=0.031)$. Considering the individual species, beech martens were detected on all sites of both habitat types and activity did not differ between the habitat types ( $D R: p=0.82 ; T P R: p=0.18)$. Red foxes were detected on only one SRC site, but on all afforestation sites in spring. Therefore, activity was significantly higher on the afforestations (DR: $p=0.015$; TPR $p=0.034)$. Badgers were detected on all afforestation sites, but were completely absent from the SRC in both seasons. Activity of hedgehogs was extremely low in both habitat types and did not differ between afforestations and SRC ( $p=0.98$ for $D R$ and $T P R$ ). The polecat was found on only one SRC site in spring. The unique detection by a single CT indicates a very low activity of this species there.

With regard to seasonal aspects of habitat utilisation of carnivores and omnivores on the SRC, there were only minor differences between winter and spring regarding both activity indices ( $D R: p=0.17$; TPR: $p=0.34$ ). Nevertheless, there were seasonal differences with regard to the number of CTs with detections of the individual species of this group and the number of sites they were detected on. In winter, beech marten was detected on only one SRC by 2 CTs (spring: all sites, 7 CTs). However, activity on this particular site was at a similar level in both seasons (DR: $p=0.40 ; T P R: p=0.37)$. Red foxes were detected on two SRC by a total of $3 \mathrm{CTs}$ in winter (spring: one site, $2 \mathrm{CTs}$ ), but activity did not differ between the seasons ( $p=0.45$ for $D R$ and TPR). Like in spring, the polecat was found on only one SRC site in winter. Activity was slightly higher, but still on a low level. Therefore, there were no significant differences between both seasons (DR: $p=0.14$; TPR: $p=0.13$ ). 
Table 4 Mean values $( \pm \mathrm{SD})$ of the measured variables $D R(=$ Detection Rate, i.e. number of detections per 100 camera nights) and $T P R$ (=Temporal Presence Rate, i.e. proportion [in \%] of nights with

\begin{tabular}{|c|c|c|c|c|c|c|}
\hline \multicolumn{2}{|l|}{ Variable } & $\mathrm{SRC}^{\mathrm{W}_{\text {INTER }}}$ & $\mathrm{SRC}^{\mathrm{SRRING}}$ & AFFORESTATION & $p^{\mathrm{S}_{\mathrm{EASON}}}$ & $p^{\mathrm{H}_{\mathrm{ABITAT}}}$ \\
\hline \multicolumn{2}{|l|}{ Total no. of species per CT } & $3.25 \pm 0.87$ & $3.42 \pm 1.0$ & $4.42 \pm 1.0$ & n.s. & $* * *$ \\
\hline \multicolumn{2}{|c|}{ No. of species per CT per camera night } & $0.67 \pm 0.34$ & $0.67 \pm 0.53$ & $0.64 \pm 0.28$ & n.s. & n.s. \\
\hline \multicolumn{2}{|l|}{ Overall $D R$ (all species) } & $175.6 \pm 128.9$ & $246.9 \pm 318.3$ & $216.1 \pm 130.1$ & n.s. & n.s. \\
\hline \multirow[t]{2}{*}{ Europ. hare } & $D R$ & $107 \pm 70$ & $131.9 \pm 197.1$ & $86.9 \pm 88$ & n.s. & n.s. \\
\hline & $T P R$ & $39.9 \pm 16.4$ & $32.8 \pm 28.3$ & $27.4 \pm 19.7$ & n.s. & n.s. \\
\hline \multirow[t]{2}{*}{ Roe deer } & $D R$ & $42.6 \pm 50$ & $62.5 \pm 47.7$ & $120 \pm 94.4$ & n.s. & $*$ \\
\hline & $T P R$ & $14.4 \pm 10.3$ & $21.7 \pm 14.3$ & $30.1 \pm 13.4$ & $* * *$ & n.s. \\
\hline \multirow[t]{2}{*}{ Europ. rabbit } & $D R$ & $19.6 \pm 41.2$ & $34.2 \pm 103$ & - & n.s. & - \\
\hline & $T P R$ & $9.1 \pm 16.4$ & $7.7 \pm 19.3$ & - & n.s. & - \\
\hline \multirow[t]{2}{*}{ Beech marten } & $D R$ & $0.97 \pm 2.71$ & $1.9 \pm 2.1$ & $2.3 \pm 5.05$ & n.s. & n.s. \\
\hline & $T P R$ & $0.78 \pm 2.07$ & $1.61 \pm 2.01$ & $1.1 \pm 1.76$ & n.s. & n.s. \\
\hline \multirow[t]{2}{*}{ Red fox } & $D R$ & $0.58 \pm 1.04$ & $0.28 \pm 0.68$ & $2.23 \pm 2.62$ & n.s. & $*$ \\
\hline & $T P R$ & $0.58 \pm 1.04$ & $0.28 \pm 0.68$ & $1.67 \pm 1.79$ & n.s. & $*$ \\
\hline \multirow[t]{2}{*}{ Europ. hedgehog } & $D R$ & - & $0.19 \pm 0.45$ & $0.18 \pm 0.43$ & - & n.s \\
\hline & $T P R$ & - & $0.19 \pm 0.45$ & $0.18 \pm 0.43$ & - & n.s \\
\hline \multirow[t]{2}{*}{ Europ. badger } & $D R$ & - & - & $3.2 \pm 2.9$ & - & - \\
\hline & $T P R$ & - & - & $2.32 \pm 2.06$ & - & - \\
\hline \multirow[t]{2}{*}{ Europ. polecat } & $D R$ & $0.58 \pm 1.04$ & $0.01 \pm 0.32$ & - & n.s. & - \\
\hline & $T P R$ & $0.58 \pm 1.04$ & $0.01 \pm 0.32$ & - & n.s. & - \\
\hline \multirow[t]{2}{*}{ Carnivores and omnivores $^{\mathrm{a}}$} & $D R$ & $3.49 \pm 3.92$ & $4.9 \pm 4.09$ & $8.6 \pm 7.72$ & n.s. & $*$ \\
\hline & $T P R$ & $3.29 \pm 3.36$ & $3.96 \pm 3.28$ & $5.86 \pm 4.18$ & n.s. & $*$ \\
\hline
\end{tabular}

Significant differences between habitat types $\left(p^{\mathrm{H}_{\mathrm{ABITAT}}}\right)$ and between seasons $\left(p^{\mathrm{S}_{\mathrm{EASON}}}\right)$ are shown by bold type, $p$-values are stated in the text. $* p<0.05$, $* * p<0.01, * * * p<0.001$, n.s. not significant

${ }^{a}$ Cumulative detections of the species red fox, badger, hedgehog, beech marten, polecat and members of the Mustelidae family which were not determinable to the species level due to poor image quality

\section{Discussion}

Most of the species found in both habitat types are common and widespread generalists which typically colonise agricultural landscapes and ecotones between farmland and woodland (Meinig et al. 2020). The presence of strictly forestassociated species was not expected due to their geographical distribution (e.g. European wildcat Felis silvestris Schreber, 1777) and because they are fairly rare throughout this region because of the low proportion of woodland (e.g. pine marten Martes martes L., 1778). Nevertheless, the young woody stands also did not seem to be an attractive habitat for common forest-associated species that have rather small territories. For instance, red squirrels, which were regularly seen in forests and hedgerows in the area surrounding the study sites. This limited attraction of SRC for forest-dwelling species is in line with the results of Christian (1997), who found significantly lower activity of forest-associated medium-sized mammals on SRC than in adjacent woodland habitats during snow-tracking studies in the USA. He concludes that SRC function largely as open habitat, rather than forest habitat, due to their simple presence of a particular species) per CT (with $n=12$ CTs for each type) on SRC (winter and spring) and afforestations (spring) 
while on the three SRC sites, which were located at a similar or even lower distance to the next woodland (cf. Table 1), no badgers were detected. Therefore, it is likely that badger territories were only present in the area surrounding the afforestations, while there were no occupied territories in the area surrounding the SRC. However, with increasing age, afforestations become more attractive for badgers and other forestassociated species, while SRC as permanently young woody habitats are probably only sporadically incorporated into their habitat use and do not represent a habitat of major importance for these species.

In his study, Christian (1997) neither found clear evidence for concentrated use nor for extensive avoidance of SRC by medium-sized carnivores such as the red fox. He therefore presumes that these species regularly pass through SRC, but are not particularly active on the sites themselves. These assumptions, based on a momentary snapshot (snowtracking), are supported by our camera trapping surveys taken over a period of 134 nights in different seasons. Our results show that carnivores like red fox, beech marten and polecat occasionally included SRC in their habitat use. However, extremely low $T P R$ and $D R$ did not indicate extended stays or intensive activities. Despite favourable structural characteristics of the surveyed SRC for small mammals (cf. Bodnor 1995; Christian et al. 1997, 1998; Moser et al. 2002; Campbell et al. 2012), carnivorous medium-sized mammals seem to prefer other habitats than the surveyed SRC for hunting. A lower abundance of small mammals on SRC in comparison to wooded and non-wooded wildlands was found by Christian et al. (1997), which supports this hypothesis. Significantly higher (although still generally low) activity of carnivorous and omnivorous species on the afforestations could therefore be related to the increased abundance of small mammals or other prey. This may be interpreted as a first indication of undisturbed development moving towards a more natural forest habitat.

Mainly, the three surveyed SRC provided attractive habitat for herbivorous farmland and forest-ecotone species (hare, roe deer, rabbit) in both seasons. Thereby, their semi-open character, caused by regular partially harvests and clone-failures, is especially favourable for inhabitants of open and semi-open landscapes such as hare and rabbit. Small-scale and structurally diverse SRC could therefore represent a suitable wildlife conservation measure for farmland species of conservation concern such as the European hare, whose populations have considerably declined in many European countries (Vaughan et al. 2003; Smith et al. 2004; Petrovan et al. 2017). A basic problem caused by the presence of herbivores on SRC is the increased risk of crop damage (Bergström and Guillet 2002). Experience from cultivation practice shows, however, that cost-intensive fencing is only necessary in exceptional cases (e.g. at high game densities or in the sensitive phase after establishment) and that damage caused by game browsing is marginal and therefore tolerable in most cases (Dimitriou and Rutz 2015).

With regard to the seasonal aspects of habitat utilisation on the SRC, the reduced presence of roe deer in winter in comparison to spring could be related to general lower food availability in this season and accordingly larger foraging areas during winter. Furthermore, in spring when roe deer give birth, the cover of SRC may also have led to a more frequent use. For the reasons leading to the higher activity of roe deer on the afforestations in spring, we can only speculate. Reasons may include, for example, a better food supply as a result of the greater variety of woody species or the presence of preferred woody species for browsing.

As a major result of our study we showed that structurally diverse and extensively managed SRC are predominantly used by the same species as young deciduous afforestations. However, most of the species found on the afforestations were detected across all sites of this habitat type and tended to be detected by more CTs than on the SRC. Most species recorded on the afforestations (roe deer, hare, badger, red fox, beech marten) were therefore constant and regular users of this habitat type. In contrast, the SRC had sporadic occurrence of some species (polecat, hedgehog and red fox), both in terms of space (number of sites and CTs with detection) and time (number of detections and nights with presence), suggesting that these species only include SRC occasionally into their habitat use. Furthermore, species occurring in both habitat types showed either similar or higher activity on the afforestations, indicating a slightly higher habitat quality for these species. Nevertheless, the results also demonstrate that SRC can be managed in a manner suitable for different large and medium-sized mammals. Major differences in $D R$ and $T P R$ between individual CTs on one and the same site indicate differences in intensity of mammal use within the study sites. Habitat features such as rides and edge-zones between open areas (e.g. headlands and rides) and woody stands seemed to be particularly attractive for the most species, especially for hare and roe deer. Therefore, measures aimed at increasing the structural diversity of SRC seem to be suitable to enhance habitat quality not only for other species groups (cf. Christian 1997; Christian et al. 1997; Hanowski et al. 1997), but also for large and medium-sized mammals. SRC designed and managed in this way may have a habitat function for large and medium-sized mammals comparable to that of young afforestations.

The extent to which our results can be generalised to commercial SRC is unclear and knowledge about the use and activity of large and medium-sized mammals within largescale commercial SRC is still limited (cf. Christian 1997). Studies on other species groups showed that commercial SRC have a lower biodiversity than small-scale experimental SRC and that most species show higher activity or abundance at the edge of the crop than in the centre (for breeding birds see 
Hanowski et al. 1997; Sage et al. 2006; Gruß and Schulz 2011, for vascular plants see Weih et al. 2003; Cunningham et al. 2004; Rowe et al. 2011). Likewise, commercial cultivation of a limited number of tree species in monotonous largescale units and a more intensive management might reduce habitat quality of SRC for mammals (Christian 1997; Christian et al. 1997) and our results, in particular the considerably increased mammalian activity found within habitat features such as rides and edge-zones, indicate this. We assume that species associated with more open habitat, such as rabbit or hare, could be negatively affected by large-scale monotonous and dense plantations, while forest-associated species would have no further advantages from lager SRC due to the already existing age limitation and the lack of habitat features of mature forests (cf. Christian 1997).

\section{Conclusions and recommendations}

Small-scale, structurally diverse and extensively managed SRC can offer attractive habitat for large and medium-sized mammals in intensively used agricultural landscapes with a limited forest proportion, particularly for herbivorous farmland and forest-ecotone species. In contrast to afforestations, SRC are regularly hindered in their development by harvesting in short cycles, which clearly limits their potential as a woody habitat. Measures to enhance habitat function and quality for mammals should therefore primarily focus on farmland and forest-ecotone species (cf. Christian 1997). The following measures, which have already been recommended by several authors (e.g. Göransson 1994; Christian et al. 1997; Hanowski et al. 1997; Sage 1998; Moser et al. 2002; Weih et al. 2003; Sage et al. 2006) for other species groups, may also improve habitat quality of SRC for large and medium-sized mammals:

- Fencing should be avoided or be restricted to the first years after establishment by mobile fencing. Tolerating minor biomass losses due to browsing could be compensated by additional income generated by hunting as a result of a more game-oriented management (cf. Sage and Robertson 1994; Bergström and Guillet 2002).

- SRC should be established in several smaller units divided by rides to create attractive and intensively frequented edge zones and corridors for wildlife crossing. Gaps can be incorporated into the plantation-design or could be tolerated in the case of clone-failures.

- Various woody species should be cultivated to increase the structural diversity of SRC and also food supply for herbivores.

- Harvesting should be carried out in sections in order to create a mixture of different age classes and growth stages. This ensures permanent availability of cover and trees for browsing, and simultaneously allows the weed layer to regenerate after harvesting.

- Measures to promote a species-rich herbaceous flora (see e.g. Gustafsson 1987) should be implemented to improve food availability for herbivores. A diverse weed layer also offers attractive conditions for small mammals and other prey of carnivorous mammal species.

Consideration of these site-level measures in the design and management of SRC enables the integration of biodiversity aspects into the crop management. Implementing such measures certainly leads to more effort for farmers or yield reduction. Measures to improve the habitat quality of SRC could, therefore, be offered as agri-environmental schemes (cf. Sage et al. 2006).

Acknowledgments We are grateful to the Lower Saxony Ministry of Food, Agriculture and Consumer Protection for the financial support of this study. We are also grateful to L. von Falkenhayn for proofreading the English manuscript and to M. Rode for his helpful comments on a former version of the manuscript. We thank M. Senne and M. Züchner for their assistance in field work. The two anonymous reviewers and the Managing Editor Mária Kazimírová made valuable comments on an earlier version of the manuscript.

Funding Open Access funding enabled and organized by Projekt DEAL. This work was supported by the Lower Saxony Ministry of Food, Agriculture and Consumer Protection (Niedersächsisches Ministerium für Ernährung, Landwirtschaft und Verbraucherschutz, ML), Grant No. 105.2-3234/1-13-4.

Availability of data and material The raw-datasets generated during and/or analysed during the current study are available from the corresponding author on reasonable request.

Code availability Not applicable.

\section{Declarations}

Approval The approval for the camera trapping survey conducted on the six study sites was kindly granted by the responsible authority for nature conservation in the Emsland district (Untere Naturschutzbehörde des Landkreises Emsland).

Conflict of interest The authors declare that they have no conflict of interest.

Open Access This article is licensed under a Creative Commons Attribution 4.0 International License, which permits use, sharing, adaptation, distribution and reproduction in any medium or format, as long as you give appropriate credit to the original author(s) and the source, provide a link to the Creative Commons licence, and indicate if changes were made. The images or other third party material in this article are included in the article's Creative Commons licence, unless indicated otherwise in a credit line to the material. If material is not included in the article's Creative Commons licence and your intended use is not permitted by statutory regulation or exceeds the permitted use, you will need to obtain permission directly from the copyright holder. To view a copy of this licence, visit http://creativecommons.org/licenses/by/4.0/. 


\section{References}

Armenteros JA, Caro J, Sanchez-Garcia C, Arroyo B, Perez JA, Gaudioso VR, Tizado EJ (2020) Do non-target species visit feeders and water troughs targeting small game? A study from farmland Spain using camera-trapping. Integr Zool 0:1-14. https://doi.org/10.1111/17494877.12496

Baum S, Weih M, Busch G, Kroiher F, Bolte A (2009) The impact of short rotation coppice plantations on phytodiversity. Appl Agric Forestry Res 59:163-170

Bergström R, Guillet C (2002) Summer browsing by large herbivores in short-rotation willow plantations. Biomass Bioenergy 23:27-32. https://doi.org/10.1016/S0961-9534(02)00027-2

Bodnor S (1995) Small mammals in short rotation energy coppice. Unpublished report, urban forestry school, University of Central England, Birmingham

Burton AC, Neilson E, Moreira D, Ladle A, Steenweg R, Fisher JT, Bayne E, Boutin S (2015) Wildlife camera trapping: a review and recommendations for linking surveys to ecological processes. $\mathrm{J}$ Appl Ecol 52:675-685. https://doi.org/10.1111/1365-2664.12432

Campbell SP, Frair JL, Gibbs JP, Volk TA (2012) Use of short-rotation coppice willow crops by birds and small mammals in Central New York. Biomass Bioenergy 47:342-353. https://doi.org/10.1016/j. biombioe.2012.09.026

Christian DP (1997) Wintertime use of hybrid poplar plantations by deer and medium-sized mammals in the midwestern U.S. Biomass Bioenergy 12:35-40. https://doi.org/10.1016/S0961-9534(96) 00062-1

Christian DP, Niemi GJ, Hanowski JM, Collins P (1994) Perspectives on biomass energy tree plantations and changes in habitat for biological organisms. Biomass Bioenergy 6:31-39. https://doi.org/10.1016/ 0961-9534(94)90082-5

Christian DP, Collins PT, Hanowski JM, Niemi GJ (1997) Bird and small mammal use of short-rotation hybrid poplar plantations. J Wildl Manag 61:171-182. https://doi.org/10.2307/3802426

Christian DP, Hoffman W, Hanowski JM, Niemi GJ, Beyea J (1998) Bird and mammal diversity on woody biomass plantations in North America. Biomass Bioenergy 14:395-402. https://doi.org/10.1016/ S0961-9534(97)10076-9

Coates A, Say A (1999) Ecological assessment of short rotation coppice. Technical report B/W5/00216/REP/1-3, funded by the Department of Trade and Industry. Harwell

Cunningham MD, Bishop JD, McKay HV, Sage RB (2004) ARBRE monitoring - ecology of short rotation coppice: four year study involving wildlife monitoring of commercial SRC plantations planted on arable land and arable control plots. Technical report B-U-1/ 00627/REP; DTI-PUB-URN-04/961, funded by the Department of Trade and Industry, London (United Kingdom). https://www.osti. gov/etdeweb/servlets/purl/20496469. Accessed 15 March 2020

Dauber J, Jones MB, Stout JC (2010) The impact of biomass crop cultivation on temperate biodiversity. Glob Change Biol Bioenergy 2: 289-309. https://doi.org/10.1111/j.1757-1707.2010.01058.x

Dimitriou I, Rutz D (eds) (2015) Sustainable short rotation coppice: a handbook. WIP Renewable Energies, München

Don A, Osborne B, Hastings A, Skiba U, Carter MS, Drewer J, Flessa H, Freibauer A, Hyvönen N, Jones MB (2012) Land-use change to bioenergy production in Europe: implications for the greenhouse gas balance and soil carbon. Glob Change Biol Bioenergy 4:372391. https://doi.org/10.1111/j.1757-1707.2011.01116.x

Edenhofer O, Pichs-Madruga R, Sokona Y, Seyboth K, Matschoss P, Kadner S, Zwickel T, Eickemeier P, Hansen G, Schlömer S, von Stechow C von (2012) Renewable energy sources and climate change mitigation: special report of the intergovernmental panel on climate change. Cambridge University Press, Cambridge
Eggers J, Tröltzscht K, Falcucci A, Maiorano L, Verburg PH, Framstad E, Louette G, Maes D, Nagy S, Ozinga WIM (2009) Is biofuel policy harming biodiversity in Europe? Glob Change Biol Bioenergy 1:18-34. https://doi.org/10.1111/j.1757-1707.2009. 01002.x

Englund O, Dimitriou I, Dale VH, Kline KL, Mola-Yudego B, Murphy F, English B, McGrath J, Busch G, Negri MC, Brown M, Goss K, Jackson S, Parish ES, Cacho J, Zumpf C, Quinn J, Mishra SK (2020) Multifunctional perennial production systems for bioenergy: performance and progress. WIREs Energy Environ 9:e375. https:// doi.org/10.1002/wene. 375

Everaars J, Frank K, Huth A (2014) Species ecology and the impacts of bioenergy crops: an assessment approach with four example farmland bird species. Glob Change Biol Bioenergy 6:252-264. https:// doi.org/10.1111/gcbb.12135

Fletcher RJ, Robertson BA, Evans J, Doran PJ, Alavalapati JRR, Schemske DW (2011) Biodiversity conservation in the era of biofuels: risks and opportunities. Front Ecol Environ 9:161-168. https://doi.org/10.1890/090091

Fry D, Slater F (2009) The biodiversity of short rotation willow coppice in the welsh landscape

Gepp N (2015) Umsetzung des kommunalen Biotopverbunds im Landkreis Emsland: Beispiele für Wegeseitenstreifen und Fließgewässer. Naturschutz und Landschaftsplanung 48:287-291

Giordano M, Meriggi A (2010) Use by small mammals of short-rotation plantations in relation to their structure and isolation. Hystrix It $\mathbf{J}$ Mamm 20:127-135. https://doi.org/10.4404/hystrix-20.2-4443

Göransson G (1994) Bird fauna of cultivated energy shrub forests at different heights. Biomass Bioenergy 6:49-52. https://doi.org/10. 1016/0961-9534(94)90084-1

Gruß H, Schulz U (2011) Brutvogelfauna auf Kurzumtriebsplantagen: Besiedlung und Habitateignung verschiedener Strukturtypen. Naturschutz und Landschaftsplanung 43:197-204

Gustafsson L (1987) Plant conservation aspects of energy forestry-a new type of land use in Sweden. For Ecol Manag 21:141-161. https:// doi.org/10.1016/0378-1127(87)90078-8

Halekoh U, Højsgaard S, Yan J (2006) The R package geepack for generalized estimating equations. J Stat Softw 15:1-11. https://doi.org/ 10.18637/jss.v015.i02

Hanowski JM, Niemi GJ, Christian DC (1997) Influence of withinplantation heterogeneity and surrounding landscape composition on avian communities in hybrid poplar plantations. Conserv Biol 11:936-944. https://doi.org/10.1046/j.1523-1739.1997.96173.x

Hardin JW, Hilbe JM (2013) Generalized estimating equations, 2nd edn. CRC Press Taylor \& Francis Group, Boca Raton

Huston MA, Marland G (2003) Carbon management and biodiversity. J Environ Manag 67:77-86. https://doi.org/10.1016/S0301-4797(02) 00190-1

Immerzeel DJ, Verweij PA, van der Hilst F, Faaij APC (2014) Biodiversity impacts of bioenergy crop production: a state-of-theart review. Glob Change Biol Bioenergy 6:183-209. https://doi.org/ 10.1111/gcbb. 12067

Keuling O, Greiser G, Grauer A, Strauß E, Bartel-Steinbach M, Klein R, Wenzelides L, Winter A (2011) The German wildlife information system (WILD): population densities and den use of red foxes (Vulpes vulpes) and badgers (Meles meles) during 2003-2007 in Germany. Eur J Wildl Res 57:95-105. https://doi.org/10.1007/ s10344-010-0403-Z

Landkreis Emsland (2016) Die Gemeinden im Landkreis Emsland. Strukturdaten im Vergleich. https://www.emsland.de/pdf files/ zahlen-unddaten/gemeindevergleich-emsland-2016_1172_1.pdf. Accessed 12 Mar 2020

Lenth R, Singmann H, Love J, Buerkner P, Herve M (2019) Emmeans: estimated marginal means, aka least-squares means. https://cran.rproject.org/web/packages/emmeans/index.html. Accessed 15 Jan 2020 
Lewandowski I (2016) The role of perennial biomass crops in a growing bioeconomy. In: Barth S, Murphy-Bokern D, Kalinina O, Taylor G, Jones M (eds) Perennial biomass crops for a resource-constrained world. Springer, Cham, pp 3-13

Meehan TD, Hurlbert AH, Gratton C (2010) Bird communities in future bioenergy landscapes of the upper Midwest. Proc Natl Acad Sci U S A 107:18533-18538. https://doi.org/10.1073/pnas.1008475107

Meinig H, Boye P, Hutterer R (2020) Rote Liste und Gesamtartenliste der Säugetiere (Mammalia) Deutschlands. Naturschutz und Biologische Vielfalt 170:0-73

Moser BW, Pipas MJ, Witmer GW, Engeman RM (2002) Small mammal use of hybrid poplar plantations relative to stand age. Northwest Sci 76:158-165

O'Connell AF, Nichols JD, Karanth KU (eds) (2011) Camera traps in animal ecology: methods and analyses. Springer, Tokyo

Petrovan SO, Dixie J, Yapp E, Wheeler PM (2017) Bioenergy crops and farmland biodiversity: benefits and limitations are scale-dependant for a declining mammal, the brown hare. Eur J Wildl Res 63:49. https://doi.org/10.1007/s10344-017-1106-5

R Core Team (2019) R Version 3.6.1: R: A language and environment for statistical computing. R Foundation for Statistical Computing, Vienna

Robertson GP, Dale VH, Doering OC, Hamburg SP, Melillo JM, Wander MM, Parton WJ, Adler PR, Barney JN, Cruse RM, Duke CS, Fearnside PM, Follett RF, Gibbs HK, Goldemberg J, Mladenoff DJ, Ojima D, Palmer MW, Sharpley A, Wallace L, Weathers KC, Wiens JA, Wilhelm WW (2008) Sustainable biofuels Redux. Science 322:49-50. https://doi.org/10.1126/science.1161525

Rowe RL, Street NR, Taylor G (2009) Identifying potential environmental impacts of large-scale deployment of dedicated bioenergy crops in the UK. Renew Sust Energ Rev 13:271-290

Rowe RL, Hanley ME, Goulson D, Clarke DJ, Doncaster CP, Taylor G (2011) Potential benefits of commercial willow short rotation coppice (SRC) for farm-scale plant and invertebrate communities in the Agri-environment. Biomass Bioenergy 35:325-336. https://doi.org/ 10.1016/j.biombioe.2010.08.046

Sage RB (1998) Short rotation coppice for energy: towards ecological guidelines. Biomass Bioenergy 15:39-47. https://doi.org/10.1016/ S0961-9534(97)10055-1

Sage RB, Robertson PA (1994) Wildlife and game potential of short rotation coppice in the UK. Biomass Bioenergy 6:41-48. https:// doi.org/10.1016/0961-9534(94)90083-3

Sage RB, Tucker K (1998) Integrated crop management of SRC plantations tomaximise crop value, wildlife benefits and other added value opportunities. Technical report B/W2/00400/REP, funded by the energy technology support unit and the Department of Trade and Industry. Harwell. https://www.osti.gov/etdeweb/servlets/purl/ 20015940. Accessed 23 April 2020

Sage RB, Cunningham M, Boatman N (2006) Birds in willow shortrotation coppice compared to other arable crops in Central England and a review of bird census data from energy crops in the UK. Ibis 148:184-197. https://doi.org/10.1111/j.1474-919X.2006. 00522.x

Sauerbrei R, Ekschmitt K, Wolters V, Gottschalk TK (2014) Increased energy maize production reduces farmland bird diversity. Glob Change Biol Bioenergy 6:265-274. https://doi.org/10.1111/gcbb. 12146

Schulz U, Gruß H, Hofmann V (2008) Wirbeltiere (Säugetiere und Brutvögel) auf Agrarholzflächen - erste Ergebnisse aus dem Projekt NOVALIS. Cottbuser Schriften zur Ökosystemgenese und Landschaftsentwicklung 6:167-169

Schulz U, Brauner O, Gruß H (2009) Animal diversity on short-rotation coppices-a review. Appl Agric For Res 59:171-182

Smith RK, Jennings NV, Robinson A, Harris S (2004) Conservation of European hares Lepus europaeus in Britain: is increasing habitat heterogeneity in farmland the answer? J Appl Ecol 41:1092-1102. https://doi.org/10.1111/j.0021-8901.2004.00976.x

Vanbeveren SPP, Ceulemans R (2019) Biodiversity in short-rotation coppice. Renew Sust Energ Rev 111:34 43. https://doi.org/10.1016/j. rser.2019.05.012b

Vaughan N, Lucas EA, Harris S, White PC (2003) Habitat associations of European hares Lepus europaeus in England and Wales: implications for farmland management. J Appl Ecol 40:163-175. https:// doi.org/10.1046/j.1365-2664.2003.00784.x

Wagener F, Heck P, Böhmer J (2013) Nachwachsende Rohstoffe als Option für den Naturschutz... Naturschutz durch Landbau? Schlussbericht zu ELKE III. Technical report 220077 09, funded by Fachagentur Nachwachsende Rohstoffe e.V. and Bundesministerium für Ernährung, Landwirtschaft und Verbraucherschutz. Birkenfeld. https://www.landnutzungsstrategie. de/wp-content/uploads/2018/07/2013-10-31_Schlussbericht_ ELKE_III_JB.pdf. Accessed 01 June 2020

Weih M, Karacic A, Munkert H, Verwijst T, Diekmann M (2003) Influence of young poplar stands on floristic diversity in agricultural landscapes (Sweden). Basic Appl Ecol 4:149-156. https://doi.org/ 10.1078/1439-1791-00157

Publisher's note Springer Nature remains neutral with regard to jurisdictional claims in published maps and institutional affiliations. 